\title{
Поперечный угловой момент нелинейной волны на поверхности раздела топологического изолятора и метаматериала
}

\author{
$\underline{\text { А.И. Маймистов }}^{1, *}$, Е.И. Ляшко ${ }^{1}$, Н.В. Быков ${ }^{2}$ \\ ${ }^{1}$ Национальный исследовательский ядерный университет «МИФИ», \\ ${ }^{2}$ Московского Государственного Технического Университета имени Н.Э. Баумана \\ *E-mail: aimaimistov@gmail.com
}

DOI: 10.31868/RFL2020.22-23

Среди характеристик электромагнитного поля наряду с потоком энергии, импульсом, важной характеристикой является угловой момент поля [1,2]. Исследования углового момента вызвано интересом к формированию пучков света с фазовыми дефектами волнового фронта излучения, и изучению возможности передачи момента вращения от поля к материальным телам. С появлением и развитием нанотехнологии это стало особенно актуально. В интегральной оптике и плазмонике роль пучков играют поверхностные волны. Естественно, возник интерес к изучению угловой момента, переносимого поверхностной волной.

В пространственно неоднородной среде, где фронт волны не плоский, волна обладает орбитальным и спиновым моментом. Оказывается, что в случае полного внутреннего отражения неоднородная (эванесцентная) волна обретает спиновый момент, хотя может быть плоской волной только в одном выделенном направлении $[3,4]$. Поверхностные волны являются как бы склеенными вдоль плоской границы раздела эванесцентными волнами и переносят как орбитальный, так и спиновый момент. Для случая поверхностной волны ТМ типа, распространяющейся вдоль поверхности раздела вакуума и отрицательно преломляющейся среды (металла или отрицательно преломляющего метаматериала) спиновый момент ненулевой и направлен ортогонально волновому вектору поверхностной волны. На поперечную ориентацию полного углового момента, который при этом является касательным к границе раздела, обратили внимание авторы статьи [3]. В случае поверхностной ТЕ волны спиновый момент равен нулю, полный угловой момент содержит только орбитальный момент, который лежит в плоскости раздела сред и поперечен по отношению к волновому вектору поверхностной волны $[3,4]$.

Известно, что при прохождении границы раздела различных топологических изоляторов (и обычными диэлектриками) происходит поворот векторов магнитного и электрического поля [5-7]. Это как бы эффект Фарадея, но поворт поляризации происходит на тонком переходном слое между двух сред. По этой причине нет отдельно поверхностных ТЕ или ТМ волн, а поверхностная волна является гибридной - все компоненты полей не нулевые.

В настоящем сообщении будет рассмотрена поверхностная волна, бегущая по плоской поверхности, которая разделяет топологический изолятором (ТИ) и гиперболическим метаматериал или оптически нелинейный метаматериал. Внимание сосредоточено на вычислении спинового углового момента, который является внутренней характеристикой электромагнитного поля волны. Основной результат состоит в том, что спиновый угловой момент не лежит в плоскости границы раздела сред [8]. Хотя, как и в случае обычных (нетопологических) сред, спиновый момент и орбитальный момент поперечны относительно направления распространения. Появление нормальной компоненты спинового углового мо- 
мента обусловлено свойствами ТИ. Известно, что на его поверхности под действием электромагнитного поля возникает поверхностный ток и наводится заряд, которых нет в обычных диэлектриках. Это приводит к изменению условий непрерывности для нормальных компонент электрической индукции и касательных компонент магнитной индукции. В результате меняется поляризация волны при переходе через границу раздела. Отдельно ТЕ и ТМ волн нет, но имеет место гибридная волна, у которой все компоненты поля ненулевые. Формально это приводит к появлению ненулевой нормальной компоненте спинового углового момента.

Для ТИ определяющим свойством является магнитоэлектрический эффект, причем коэффициент пропорциональности между поляризацией (намагниченностью) и напряженностью магнитного (электрического) поля квантован в единицах постоянной тонкой структуры. Эта дискретность проявляется в характеристиках поверхностной волны. Например, дисперсионное соотношение расщепляется на ряд ветвей, нумеруемых целыми нечетными числами. Та же дискретность присутствует в компонентах электрического и магнитного поля поверхностных волн. Надо заметить, что присутствие ТИ проявляется в дискретности этих компонент $[9,10]$. В отличие от мод волновода, дискретность характеристик поверхностной волны (постоянная распространения, поток энергии, полный угловой момент) обусловлена свойствами ТИ, а не интерференцией волн, захваченных волноводом. Какая из ветвей дисперсионного уравнения и каким образом можно осуществить переключение между поверхностными волнами, отвечающими разным топологическим числам - пока не решенная задача.

Влияние керровской нелинейности диэлектрика, соприкасающегося с ТИ, на образование поверхностной волны учитывалось в [10,11]. Ненулевая нормальная компонента вектор спинового углового момента и ее дискретность сохраняются. Малые возмущения амплитуды поверхностной волны эволюционируют в кноидальные волны конечной амплитуды, для которых период осцилляций зависит от топологического числа [11].

Исследование выполнено при поддержке Российского фонда фундаментальных исследований (грант № 18-02-00921)

\section{Литература}

[1] S.M. Barnett, J. Mod. Opt. 57, 1339-1343 (2010)

[2] A.M. Yao, M.J. Padgett, Adv. Opt. \& Photon. 3, 161-204 (2011)

[3] K.Y. Bliokh, F. Nori, Phys. Rev. A. 85. 061801(R) (2012)

[4] K.Y. Bliokh, F. Nori, Physics Reports 592, 1-38 (2015)

[5] M. Z. Hasan, C. L. Kane, Rev.Mod.Phys. 82, 3045 (2010)

[6] Xiao-Liang Qi, T. L. Hughes, Shou-Cheng Zhang, Phys.Rev. B. 78, 195424 (2008)

[7] A. Karch, Phys.Rev. B. 83, 245432 (2011)

[8] А.И. Маймистов, Е.И. Ляшко, Оптика и спектроскопия 125, 795-799 (2018)

[9] А.И. Маймистов, Е.И. Ляшко, Оптика и спектроскопия 126, 578-583 (2019)

[10] А.И. Маймистов, Е.И. Ляшко, Известия РАН, сер.физ. 84, №3, 328-331 (2020)

[11] А.И. Маймистов, Е.И. Ляшко, С.О. Елютин, Изв.РАН сер.физ. 84, 7-10 (2020) 